\title{
Photoelectrocatalytic Degradation of Indanthrene Blue Dye using Ti/Ru-Based Electrodes Prepared by a Modified Pechini Method
}

\author{
Marilia M. S. Pupo, ${ }^{a}$ Lucas S. da Costa, ${ }^{a}$ Aíle C. Figueiredo, ${ }^{a}$ Ronaldo S. da Silva, ${ }^{b}$ \\ Frederico G. C. Cunha, ${ }^{c}$ Katlin I. B. Eguiluz $z^{a}$ and Giancarlo R. Salazar-Banda ${ }^{* a}$ \\ ${ }^{a}$ Instituto de Tecnologia e Pesquisa, Programa de Pós-Graduação em Engenharia de Processos, \\ Universidade Tiradentes, 49032-490 Aracaju-SE, Brazil \\ ${ }^{b}$ Laboratório de Materiais Cerâmicos Avançados, Departamento de Física, \\ Universidade Federal de Sergipe, 49100-000 São Cristóvão-SE, Brazil \\ ${ }^{c}$ Departamento de Física, Universidade Federal de Sergipe, \\ CP 353, 49100-000 São Cristóvão-SE, Brazil
}

\begin{abstract}
Fotoeletrodos foram usados para tratar efluentes têxteis sintéticos contaminados com corante azul indantreno. Dois meios de tratamento foram usados $\left(\mathrm{NaCl} \mathrm{e} \mathrm{Na}_{2} \mathrm{SO}_{4}\right)$ com variações de temperatura, $\mathrm{pH}$, densidade de corrente, concentrações de corante e de cloreto. Um método de Pechini modificado foi aplicado para obter os eletros de Ti/Ru (Ti, $\mathrm{Ru}, \mathrm{Ti}_{0.5} \mathrm{Ru}_{0.5}, \mathrm{Ti}_{0.75} \mathrm{Ru}_{0.25}$ e $\mathrm{Ti}_{0.25} \mathrm{Ru}_{0.75}$ ) contendo nanoparticulas de $\mathrm{TiO}_{2}$ anatase e a análise de degradação de cor foi realizada. Caracterizações física (microscopia de força atômica e difratometria de raios X) e eletroquímica (voltametria cíclica) foram feitas. As condições que geraram maior remoção de cor para o sistema apresentado foram $\mathrm{NaCl} 0,05 \mathrm{~mol} \mathrm{~L}^{-1}, 100 \mathrm{~mA} \mathrm{~cm}^{-2}, 35^{\circ} \mathrm{C}$ e $\mathrm{pH} 7$, independente da concentração de corante para o eletrodo de $\mathrm{Ti}_{0.25} \mathrm{Ru}_{0.75}$.
\end{abstract}

Photoelectrodes were used to treat synthetic textile wastewater contaminated with indanthrene blue dye. Two media of treatment were used $\left(\mathrm{NaCl}\right.$ and $\left.\mathrm{Na}_{2} \mathrm{SO}_{4}\right)$, with variations on temperature, $\mathrm{pH}$, current density, dye and chloride concentration. A modified Pechini method was applied to obtain Ti/Ru-based electrodes ( $\mathrm{Ti}, \mathrm{Ru}, \mathrm{Ti}_{0.5} \mathrm{Ru}_{0.5}, \mathrm{Ti}_{0.75} \mathrm{Ru}_{0.25}$ and $\mathrm{Ti}_{0.25} \mathrm{Ru}_{0.75}$ ) containing anatase $\mathrm{TiO}_{2}$ nanoparticles and a color degradation analysis was done. Physical (atomic force microscopy and X-ray diffractometry) and electrochemical characterizations (cyclic voltammetry) were considered. The condition that yielded highest color removal for the system presented $0.05 \mathrm{~mol} \mathrm{~L}^{-1} \mathrm{NaCl}, 100 \mathrm{~mA} \mathrm{~cm}{ }^{-2}, 35^{\circ} \mathrm{C}$ and $\mathrm{pH}$ 7, independent of the dye concentration for the $\mathrm{Ti}_{0.25} \mathrm{Ru}_{0.75}$ electrode.

Keywords: nanostructured materials, indanthrene blue, dye degradation, oxide anodes, titanium dioxide nanoparticles

\section{Introduction}

A sum of around 750,000 tons of dye is consumed every year by a variety of textile, leather dye, paper production, food technology and cosmetics, among other industries. Dyes are composed of chromophores and other structures responsible for its fixation to the fiber. The most commonly used chromophore are the azo dyes which typically have a $-\mathrm{N}=\mathrm{N}-$ group in which nitrogen atoms are bonded to aromatic system. ${ }^{1}$

*e-mail: gianrsb@gmail.com
From 20 to $30 \%$ of the known dyes can be determined by its chromophore group, in which the azo dyes represent $70 \%$ of these, and the antraquinones represent $15 \%$ of this group of dyes used industrially. ${ }^{2}$ The antraquinones are characterized by their condensed atomic structure that yields a stronger resistance to biodegradation. ${ }^{3}$ They are used commercially for the coloration of cotton and cellulose fibers, having a very representative health risk due to their secondary products, which include aromatic amines with a very well documented proven carcinogenic potential. ${ }^{4}$

The high resistance of this group to microbial treatments and its high stability in presence of sunlight make it 
necessary to develop powerful treatment methods able to decompose these compounds without yielding other contaminants that can cause environmental damages. ${ }^{1}$

The highest impact from these compounds is considered water contamination. Water pollution is understood as the degradation of its environmental qualities as a result of activities, which direct or indirectly dispose inappropriate matters or energy to the water not meeting the environmental standards established. ${ }^{5}$

In this scenario, alternative wastewater treatments are needed and among the choices presented, the electrochemical forms of treatment are preferred due to their non use of chemical reagents, and dependence of only electrodes which have as main feature their noncontamination potential. ${ }^{1}$

Photoelectrocatalysis consists of a system in which a metal based thin film is irradiated with UV light to produce electron excitation and positively charge holes, making them available for organic and water oxidation yielding $\mathrm{OH} .{ }^{1}$

The anatase form of $\mathrm{TiO}_{2}$ has been used in photocatalysis for light-induced oxidation of organic pollutants. The most attractive features of this semiconductor material are its low cost, low toxicity and wide band gap $(3.2 \mathrm{eV})$ preventing photocorrosion and good stability. ${ }^{1}$

The photocatalysis occurs as the irradiation of anatase $\mathrm{TiO}_{2}$ nanoparticles by $\mathrm{UV}$ protons $(\lambda<380 \mathrm{~nm})$ necessary to promote an electron from the valence band to the conduction band $\left(\mathrm{e}_{\mathrm{CB}}^{-}\right)$generating a positive vacancy $\left(\mathrm{V}_{\mathrm{VB}}{ }^{+}\right),{ }^{6}$ as seen below:

$\mathrm{TiO}_{2}+h v \rightarrow \mathrm{e}_{\mathrm{CB}}{ }^{-}+\mathrm{V}_{\mathrm{VB}}{ }^{+}$

Additionally, organic materials can be oxidized by a direct route through the vacancy or by the formation of a heterogeneous hydroxyl radical formed by the interaction between the photogenerated vacancy and the adsorbed water: ${ }^{6}$

$\mathrm{V}_{\mathrm{VB}}{ }^{+}+\mathrm{H}_{2} \mathrm{O} \rightarrow \cdot{ }^{\bullet} \mathrm{OH}+\mathrm{H}^{+}$

On the other hand, in electrochemical treatment systems, the main problem of organic compound oxidation processes in larger scales is the development of adequate electrodes, since these processes occur in high anodic potential, in which a high electrochemical and physical stability of the electrode is required.

In this sense, the Pechini method allows the production of stable electrodes in relatively low temperatures and with controlled characteristics (stoichiometry, homogeneity and particle sizes). ${ }^{7}$
Searching to fulfill the requirements of high catalytic activity together with high stability, the present study seeks to develop electrodes containing $\mathrm{TiO}_{2}$ nanoparticles and $\mathrm{Ti}$ and/or Ru compounds deposited as thin films on Ti substrates for use in photoelectrocatalytic treatment of wastewaters contaminated with indanthrene blue. The electrodes were synthesized according to a modified Pechini method, which consists of polyester preparation that is obtained from adding citric acid (CA) to ethylene glycol (EG) on which an alkaloid metal is dissolved. The paste obtained is deposited in a titanium support and heated to $450-500{ }^{\circ} \mathrm{C}$, so that the organic additives can be carbonized and replaced by pores, which will substantially increase the superficial area of the electrode. ${ }^{7}$

These electrodes must be able to resist to the operation conditions and yield a potentially non-environmentally damaging system able to treat contaminated wastewater, reducing its dye presence. The prepared electrodes containing different compositions were characterized by atomic force microscopy (AFM), X-ray diffractometry (XRD) and cyclic voltammetry (CV). In addition, the influence of different operating conditions, like the dye and electrolyte concentrations, the current density applied, the $\mathrm{pH}$ and the temperature on the removal of the indanthrene blue were studied.

\section{Experimental}

For the present study, the chosen dye was indanthrene blue (CAS No. 81-77-6), with a melting point between 470-500 ${ }^{\circ} \mathrm{C}$, solubility of $0.1 \mathrm{~g} 100 \mathrm{~mL}^{-1}$ in water at environment temperature and soluble also in concentrated sulfuric acid beside alkaline solutions. The dye structure can be seen in Figure 1.<smiles></smiles>

Figure 1. Indanthrene blue CAS No. 81-77-6.

\section{Synthesis of the electrodes}

The electrodes were synthesized according a modified Pechini method. Initially, the titanium supports were submitted to a previous treatment in order to clean and 
standardize the surface of the support, also removing the insulating superficial layer of titanium oxides/hydroxides spontaneously formed. Thus, first, the titanium support was abraded with a sandpaper of 600 granulometry followed by a sandpaper of 1000 granulometry. Second, it was washed in ultrapure water (Milli-Q) and immersed in isopropyl alcohol. Third, once rinsed with ultrapure water, it was immersed in $\mathrm{HCl}$ solution (20\%) for $20 \mathrm{~min}$ at around $100{ }^{\circ} \mathrm{C}$ with manual temperature and stirring regulation. Fourth, the electrode was again washed with ultrapure water and then immersed in oxalic acid (10\%) for $5 \mathrm{~min}$ at around $100{ }^{\circ} \mathrm{C}$ with manual temperature and stirring regulation. Finally, it was washed several times with ultrapure Milli-Q water and dried for $10 \mathrm{~min}$ at $130^{\circ} \mathrm{C}$ in an oven (Quimis, Q318 D24).

Ruthenium chloride (Sigma-Aldrich, Ru content 50\%) and/or titanium isopropoxide (Sigma-Aldrich, 97\%) with a fixed amount of nanoparticles of titanium dioxide (Degussa P25) were mixed allowing the formation of slurries. Thus, five different electrodes were synthesized: $\mathrm{Ti} / \mathrm{TiO}_{2}-\mathrm{TiO}_{2}, \mathrm{Ti} / \mathrm{TiO}_{2}-\mathrm{RuO}_{2}, \mathrm{Ti} / \mathrm{TiO}_{2}-\left(\mathrm{TiO}_{2}\right)_{0.5}-\left(\mathrm{RuO}_{2}\right)_{0.5}$, $\mathrm{Ti} / \mathrm{TiO}_{2}-\left(\mathrm{TiO}_{2}\right)_{0.25}-\left(\mathrm{RuO}_{2}\right)_{0.75}$ and $\mathrm{Ti} / \mathrm{TiO}_{2}-\left(\mathrm{TiO}_{2}\right)_{0.75}$ $\left(\mathrm{RuO}_{2}\right)_{0.25}$, where $\mathrm{TiO}_{2}$ represents the commercial titanium dioxide nanoparticles. For matter of simplifications from hereafter the nanoparticles $\left(\mathrm{TiO}_{2}\right)$, which are present in all electrodes, will be omitted. Therefore, an electrode composed of $\mathrm{Ti} / \mathrm{TiO}_{2}-\left(\mathrm{TiO}_{2}\right)_{0.5}-\left(\mathrm{RuO}_{2}\right)_{0.5}$, will be called $\mathrm{Ti}_{0.5} \mathrm{Ru}_{0.5}$. The methodology applied to synthesize all five electrodes will be further described.

For the ruthenium electrode, a precursor solution was prepared using $0.001 \mathrm{~mol}$ of ruthenium chloride $\left(\mathrm{RuCl}_{3}\right)$, under agitation at $90^{\circ} \mathrm{C}$, added to a solution of $\mathrm{CA}$ and $\mathrm{EG}$ (previously mixed under agitation at $60^{\circ} \mathrm{C}$ ) and stirred for nearly $1 \mathrm{~h}$ at molar ratio of $\mathrm{RuCl}_{3} / \mathrm{CA} / \mathrm{EG}$ (1:3:10).

Then, by mixing the determined amount of titanium dioxide in powder $(0.2797 \mathrm{~g})$ in the solution previously prepared with ruthenium chloride under agitation and heating, the slurry with ruthenium $(1 \mathrm{~mol})$ and titanium dioxide nanoparticles $(7 \mathrm{mols})$ was mixed until it reached an homogeneous form and was finally ready.

For the titanium electrode, a precursor solution was prepared using $0.001 \mathrm{~mol}$ of titanium isopropoxide added to EG under agitation at $60^{\circ} \mathrm{C}$ until complete dissolution. Later on, the progressive addition of CA at $90{ }^{\circ} \mathrm{C}$ until the solution was clear, following the molar ratio of $\mathrm{TiO}_{2} / \mathrm{CA} / \mathrm{EG}$ (1:4:16), were carried out.

The slurry is obtained by adding nanoparticles of $\mathrm{TiO}_{2}$ in powder to the precursor solution, in which for each $1 \mathrm{~mol}$ of titanium isopropoxide, there were $3.5 \mathrm{mols}$ of titanium dioxide in powder, under agitation at $90{ }^{\circ} \mathrm{C}$ until the solution becomes clear.
The use of a vacuum chamber is needed for the $\mathrm{Ti}$ precursor solution preparation due to rapid hydrolysis ${ }^{8}$ of the titanium isopropoxide used for the precursor solution preparation. By creating an inert environment, it is possible to prepare the solution ensuring that the titanium isopropoxide is properly dissolved in EG. Using a syringe, the desired amount was dissolved in pre-heated EG, and then $\mathrm{CA}$ was added and dissolved $\left(90^{\circ} \mathrm{C}\right)$ under agitation.

For the $\mathrm{Ti}_{0.5} \mathrm{Ru}_{0.5}$ electrode, the addition of $0.0005 \mathrm{~mol}$ of titanium isopropoxide and $0.0005 \mathrm{~mol}$ of $\mathrm{RuCl}_{3}$ from the precursor solution after previous preparation of each solution individually. Therefore, the preparation of ruthenium and titanium pastes was repeated. However, the molar concentration of $\mathrm{RuCl}_{3}$ was now of $0.0005 \mathrm{~mol}$ for the ruthenium solution and the concentration of $\mathrm{TiO}_{2}$ was $0.0005 \mathrm{~mol}$ for the titanium solution. Finally, both solutions are mixed and homogenized for the posterior addition of the commercial $\mathrm{TiO}_{2}$ nanoparticles.

For the $\mathrm{Ti}_{0.25} \mathrm{Ru}_{0.75}$ electrode, the same methodology used in the previous electrode is repeated but the molar concentrations of $\mathrm{RuCl}_{3}$ and $\mathrm{TiO}_{2}$ was now of 0.00075 and 0.00025 , respectively. The same procedure was repeated for the $\mathrm{Ti}_{0.75} \mathrm{Ru}_{0.25}$ electrode but with molar concentrations for $\mathrm{RuCl}_{3}$ and $\mathrm{TiO}_{2}$ of 0.00025 and 0.00075 , respectively.

All the slurries were deposited on the titanium support and then taken to an oven (Quimis) for $30 \mathrm{~min}$ at $130^{\circ} \mathrm{C}$, the temperature was elevated to $250{ }^{\circ} \mathrm{C}$ for $10 \mathrm{~min}$ when the adherence of the solutions to the support is seen, and a posterior elevation of the temperature up to $400{ }^{\circ} \mathrm{C}$ for $1 \mathrm{~h}$ was done. This process was repeated three times and it sought to obtain an electrode with a surface of high porosity.

\section{Physical characterization}

The electrode morphology was analyzed by AFM, using an AFM CP-Research (Veeco) equipment applying a constant force of $50 \mathrm{nN}$ at a scanning rate of $1 \mathrm{~Hz}$. The measurements were done in a CP-Research STM (Thermos-Veeco) in contact mode. The results obtained represent topographical images of the surfaces.

With this result, it is possible to analyze the morphology, roughness, granulometry and grain organization of the surface of the electrode, which are of great interest in order to justify certain behaviors of the electrode.

Further assessments were carried out by XRD analysis by which it is possible to determine the effective crystalline surface composition of the electrode by comparison of the results with the data obtained from the Joint Committee on Powder Diffraction Standards (JCPDS). XRD patterns were taken in a universal diffractometer Rigaku Ultima + RINT 2000/PC, operating with $\mathrm{Cu}$ 
$\mathrm{K}_{\alpha}$ radiation $(\lambda=0.15406 \mathrm{~nm})$ generated at $50 \mathrm{kV}$ and $50 \mathrm{~mA} \mathrm{~cm}{ }^{-2}$. The scans were carried out at $2^{\circ} \mathrm{min}^{-1}$ for $2 \theta$ values between 20 and $80^{\circ}$.

\section{Electrochemical characterization}

The electrochemical measures were taken in a potentiostat/ galvanostat Autolab model PGSTAT 302N, on General Purpose Electrochemical System version 4.9, developed by Eco Chemie. One electrochemical cell compartment is made of Pyrex ${ }^{\circledR}$ glass, with a Teflon cover, which has holes for the working, reference and counter-electrodes, as well as for the entrance and exit of $\mathrm{N}_{2}$ gas.

The working electrodes were the dimensionally stable anodes, or better, the photoanodes, prepared for this study, the counter electrode was a $2 \mathrm{~cm}^{2}$ platinum plate and the reference electrode was a hydrogen electrode in the same solution (HESS) immersed into a Luggin capillary. All potentials are referred to the standard hydrogen electrode (SHE). The solutions were prepared with analytical grade reagents without further purification and water supplied by a Milli-Q system from Millipore Inc.

Cyclic voltammetry was applied to determine the electrochemical behavior of the electrodes in presence and absence of dye to estimate the oxidation potential of each sample. Therefore, the initial photoelectrolysis was carried out in a current density chosen from the cyclic voltammetry.

\section{Photoelectrochemical degradation of indanthrene blue}

A laboratorial scale photoelectrochemical system was elaborated to carry on the experiment, and can be seen in Figure 2. The scheme built in a closed lab aims to treat an industrial wastewater contaminated with indanthrene blue C-B (Dystar) $60 \mathrm{ppm}$, the characteristics were previously described. The system is composed of a current stabilizing source Minipa MPS-3003 (5), a UV lamp of 250 W (3), a photoelectrochemical cell encapsulated with facilities (6) for a thermostat bath, a counter electrode (2) and the work electrode (1), and a magnetic stirrer (4). The light source was positioned at ca. $4 \mathrm{~cm}$ distance from the source at the location of the working electrode inside the electrochemical cell with a quartz tube (without solution).

Experiments were carried out in environmental conditions for $3 \mathrm{~h}$ and aliquots were extracted at $0,5,10$, $15,30,60,120$ and $180 \mathrm{~min}$. The concentration of the dye in the solution was determined by measuring the absorbance of the dye solution in the aliquots using a spectrophotometer (Hatch DR-2500) in order to determine the performance of the treatment system. The spectrophotometric analyses were carried out at a wavelength of $365 \mathrm{~nm}$, estimated to be

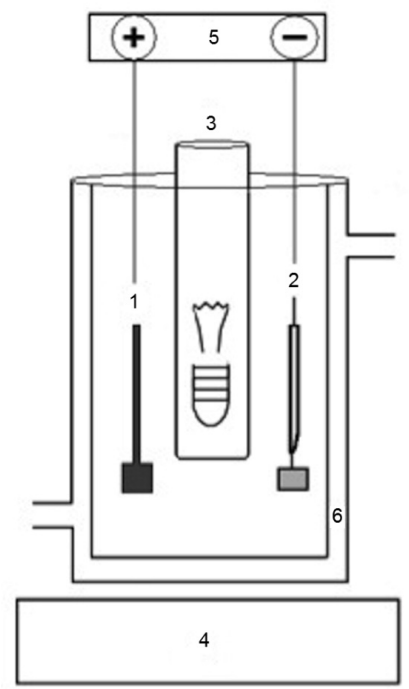

Figure 2. Scheme of the photoelectrocatalytic treatment system in a laboratorial scale: (1) working electrode, (2) platinum counterelectrode, (3) UV lamp, (4) magnetic stirrer, (5) power supply and (6) photoelectrochemical cell.

the representative wavelength for the dye studied. Similar studies seen in the literature using indanthrene blue RS dye as target compound for removal ${ }^{9}$ commonly uses the same wavelength.

The effluent prepared in our lab was indanthrene blue C-BC (Dystar) dissolved in a solution of $0.1 \mathrm{~mol} \mathrm{~L}^{-1}$ sodium chloride or of $0.03 \mathrm{~mol} \mathrm{~L}^{-1}$ sodium sulfate. All the electrodes obtained were analyzed in a system with dye dissolved in sodium chloride or dissolved in sodium sulfate solutions.

Experiments were carried out with the most efficient electrode; variations in the system temperature, concentration, $\mathrm{pH}$ and current were done to analyze the system response and to determine the condition of the ideal system.

\section{Results and Discussion}

Physical characterization

Atomic force microscopy is well known as a reliable source able to characterize the surface of a variety of materials in 2D topographic images. From the AFM images, the roughness of the samples are determined and therefore, the electrode with highest surface area and most relevant for the study can be determined. Figure 3 shows AFM topographic panoramic visions of the electrode surfaces analyzed in a $10 \times 10 \mu \mathrm{m}$ area. These images display typical features of deposits synthesized ${ }^{10}$ by the Pechini method, ${ }^{7}$ with very rough surfaces. These are very important from a catalytic point of view since a higher suface area related to 
a rougher surface can be associated to higher degradation of the studied dye.

Figure 3 shows the $\mathrm{Ru}, \mathrm{Ti}_{0.5} \mathrm{Ru}_{0.5}, \mathrm{Ti}_{0.75} \mathrm{Ru}_{0.25}, \mathrm{Ti}_{0.25} \mathrm{Ru}_{0.75}$ electrodes presented roughness of $0.12,0.24,0.20$ and $0.80 \mu \mathrm{m}$, respectively. From the roughness results, it is possible to presume that the ruthenium electrode although showing the smallest roughness of all, when combined with titanium shows an increased surface area. In this sense, the higher the amount of ruthenium combined with titanium, the higher is the roughness found. Therefore, although ruthenium is widely known for its use as an electrochemical catalyst, in the present experiment, and according to the results found by AFM, it is expected that the $\mathrm{Ti}_{0.25} \mathrm{Ru}_{0.75}$ electrode having the highest roughness present an improved catalytic efficiency when compared to ruthenium.

Previous studies ${ }^{11}$ indicated that electrodes suffering deposition of pastes containing titanium propoxide followed of heat treatment present highly porous surfaces, thus, somehow during the heating step, titanium propoxide transforms into titanium oxide, which leads to an increase of surface roughness. ${ }^{12}$

In search to verify the formation of crystalline oxides deposited on the electrode surfaces prepared by modified
Pechini method, XRD analyses were taken. Figure 4 shows the diffractograms obtained for $\mathrm{Ti}_{0.25} \mathrm{Ru}_{0.75}$ (b) $\mathrm{Ti}_{0.5} \mathrm{Ru}_{0.5}$, (c) ruthenium and (d) $\mathrm{Ti}_{0.75} \mathrm{Ru}_{0.25}$ with a calcination temperature of up to $400{ }^{\circ} \mathrm{C}$.

Comparing the peaks seen in Figure 4 with the standards of the JCPDS, it could be seen that ruthenium oxide formed during thermal decomposition at $400{ }^{\circ} \mathrm{C}$ was of rutile structure (JCPDS-71-2273). The diffractograms also show $\mathrm{TiO}_{2}$ in anatase form (JCPDS-84-1286) related to the commercial anatase $\mathrm{TiO}_{2}$ nanoparticles deposited as photocatalyst. Some signals of $\mathrm{Ti}_{3} \mathrm{O}_{5}$ were also observed (JCPDS-82-1138) which can be formed by the deposition of the Pechini precursors as already observed for sol-gel methods, ${ }^{13}$ or maybe formed during the thermal treatment from the anatase $\mathrm{TiO}_{2}$ nanoparticles. The peaks related to metallic Ti (JCPDS-01-1197) are due to the metallic Ti substrate.

The non-identified peaks can be related to chlorides, since the most common impurities seen in the literature are remaining chlorides from the thermal decomposition. This contamination is dependent of the oxide calcination temperature, ${ }^{14}$ in which the higher the temperature, the higher the presence of remaining chlorides.
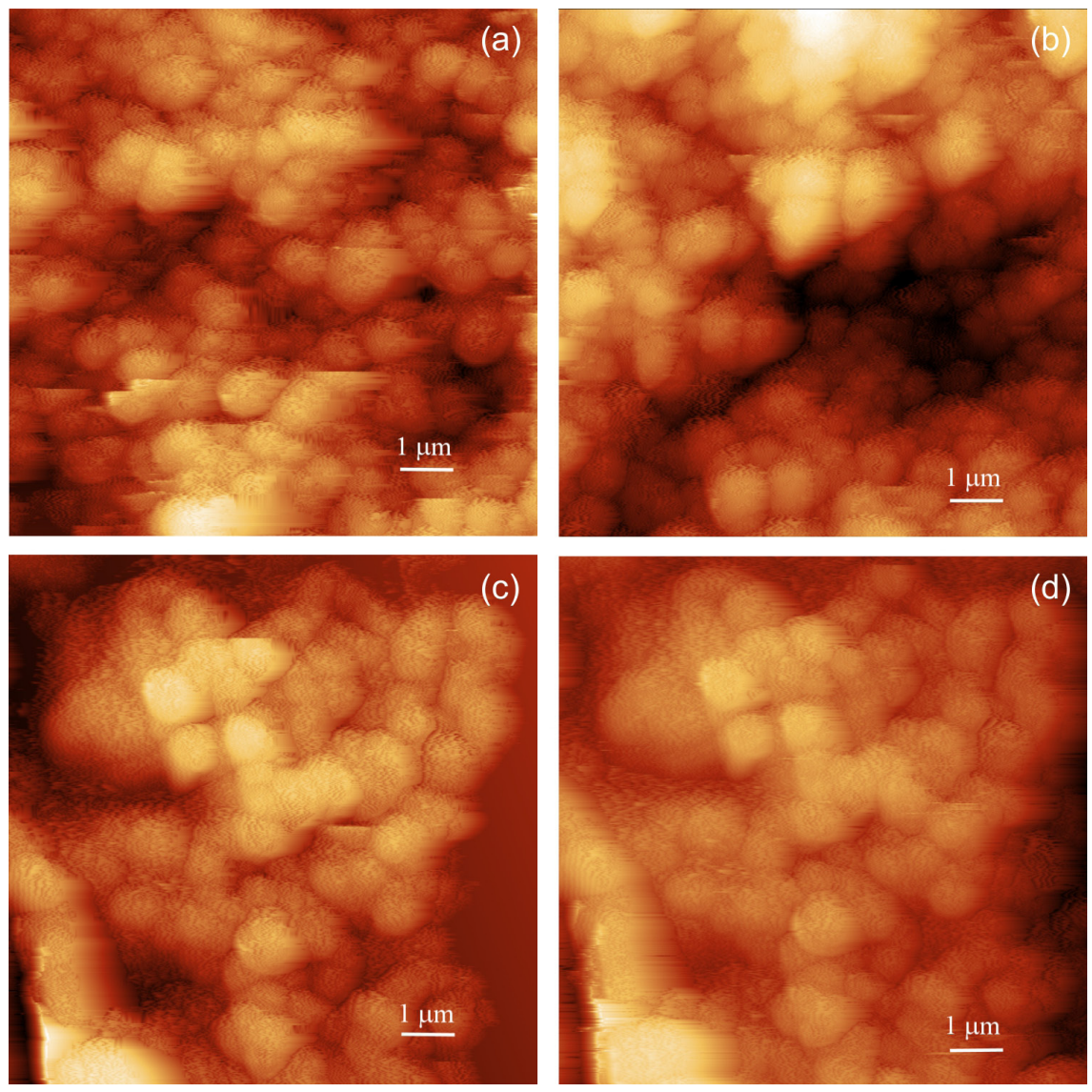

Figure 3. AFM 2D topographic images from a panoramic view taken by contact mode in a $10 \mu \mathrm{m} \times 10 \mu \mathrm{m}$ area for (a) ruthenium, (b) $\mathrm{Ti}_{0.5} \mathrm{Ru}_{0.5},(\mathrm{c}) \mathrm{Ti}_{0.25} \mathrm{Ru}_{0.75}$ and (d) $\mathrm{Ti}_{0.75} \mathrm{Ru}_{0.25}$ electrodes. 
Very intense $\mathrm{TiO}_{2}$ peaks are seen in all XRD results taken for all the electrodes, this is due to the greater amount of this commercial compound added in the synthesis of the electrodes described previously in the modified Pechini methodology adopted.

\section{Cyclic voltammetry studies}

The electrochemical evaluations of the electrodes, in Figures 5 and 6, were carried out by cyclic voltammetry. The cyclic voltammograms were taken for each electrode in presence and absence of dye in both: $0.1 \mathrm{~mol} \mathrm{~L}^{-1} \mathrm{NaCl}$ and $0.03 \mathrm{~mol} \mathrm{~L}^{-1} \mathrm{Na}_{2} \mathrm{SO}_{4}$ medium.

In general, the results found for $\mathrm{NaCl}$ medium presented better outcomes, showing higher potentials than those seen for $\mathrm{Na}_{2} \mathrm{SO}_{4}$, therefore, the data from the later are not shown. Further explanation on the reasons why $\mathrm{NaCl}$ presentssuch better outcomes will be done hereafter.

In most cases, the current density of the electrodes reduces in presence of dye, due to the fact that the organic
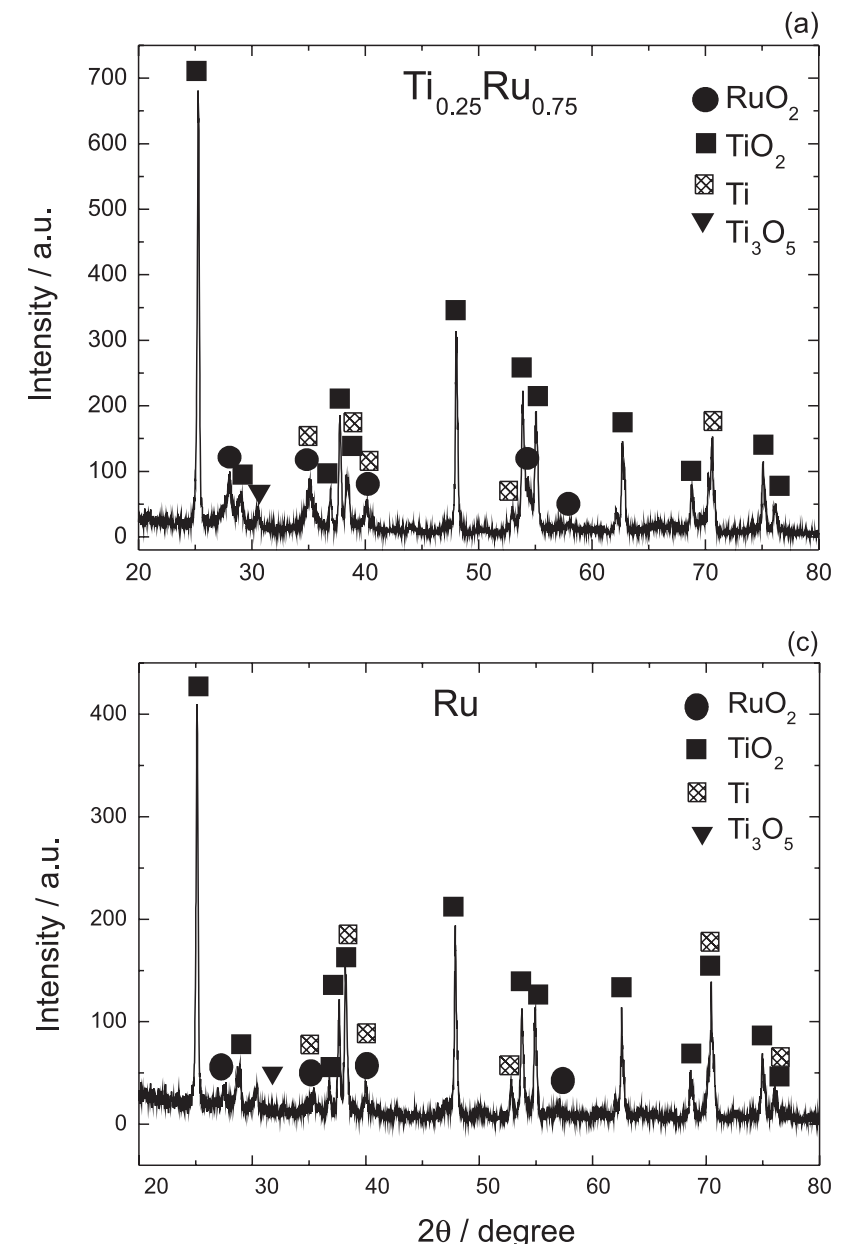

(c) composites present a strong adsorption to the electrode surface capacity, which eventually reduces the exposed surface of the electrode and therefore a reduction in the active sites is seen. ${ }^{2}$

This reduction of current density is mostly greater in oxygen evolution reaction (OER) regions, which are areas that need active sites available at the surface of the electrode for the initial adsorption of oxygen ions. Therefore, the reduction of these particular areas confirms the strong dye adsorption theory. ${ }^{1}$

Figure 5a shows voltammograms obtained for $\mathrm{Ru}$ electrode, in absence (full line) and presence of dye (dotted line), in which a mainly capacitive behavior is seen due to the high surface area of the electrodes. These high current densities are related to the capacitive loading of the electrode combined with the redox processes due to $\mathrm{Ru}$ oxides present in the electrode. Similar curves can be found in the literature, ${ }^{15}$ also stating that the strong organic compound adsorbed on the electrode surface will reduce the exposed surface of the electrode and thus a reduction in the current will be seen.
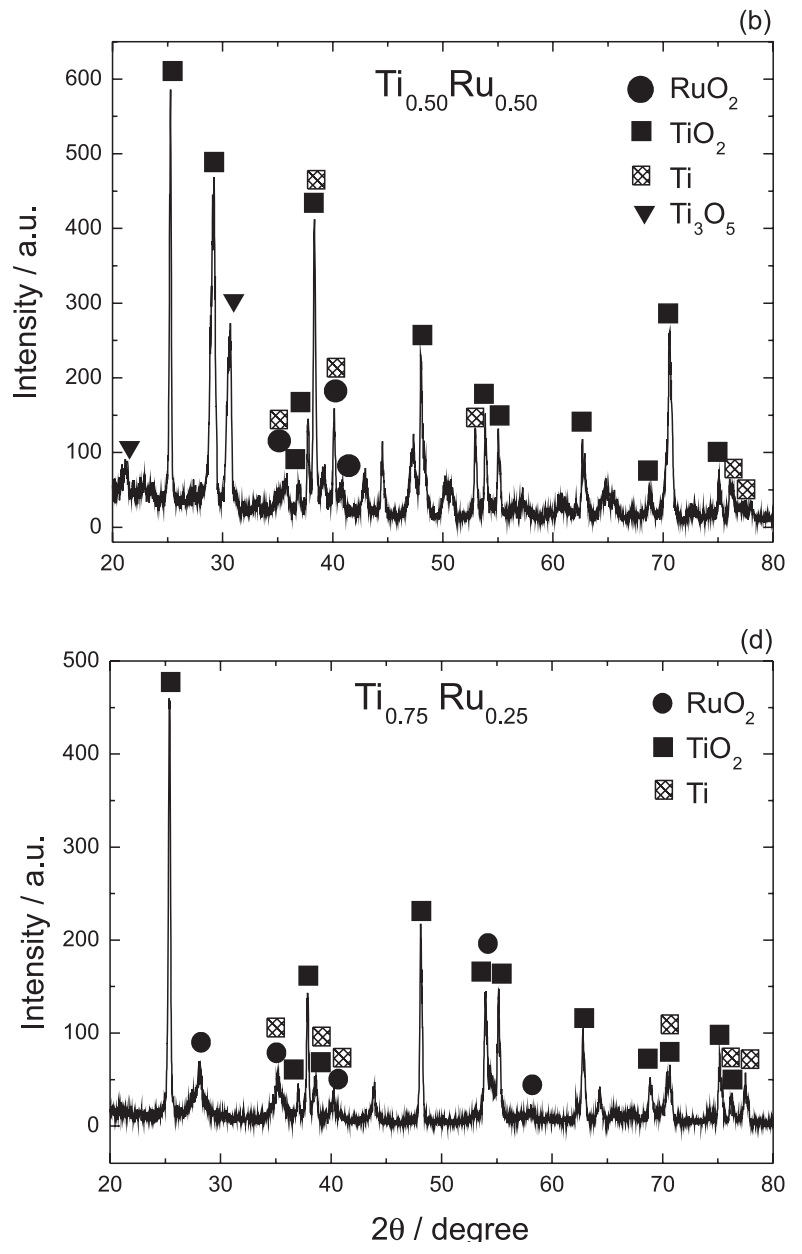

Figure 4. X-ray diffractograms for (a) $\mathrm{Ti}_{0.25} \mathrm{Ru}_{0.75}$ (b) $\mathrm{Ti}_{0.5} \mathrm{Ru}_{0.5}$, (c) ruthenium and (d) $\mathrm{Ti}_{0.75} \mathrm{Ru}_{0.25}$ electrodes. 
(a)

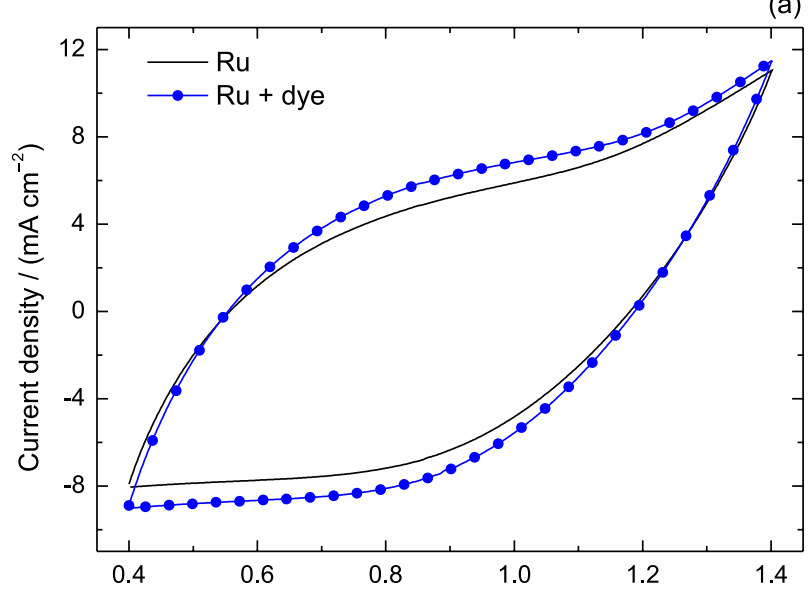

(c)

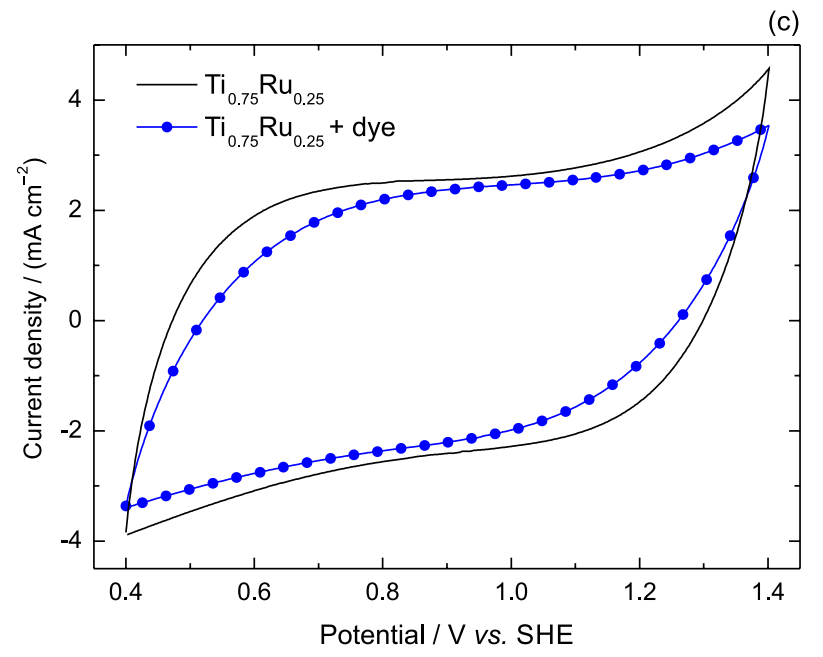

(b)

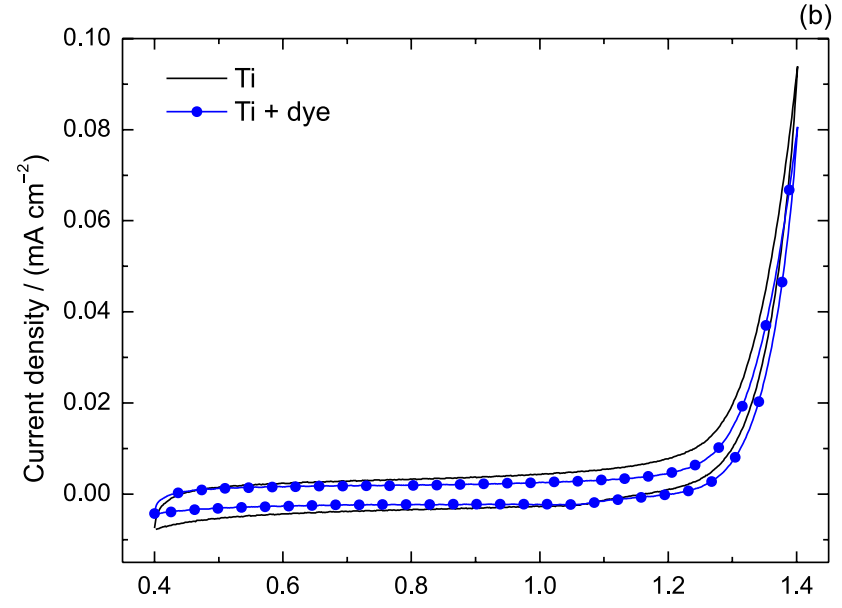

(d)

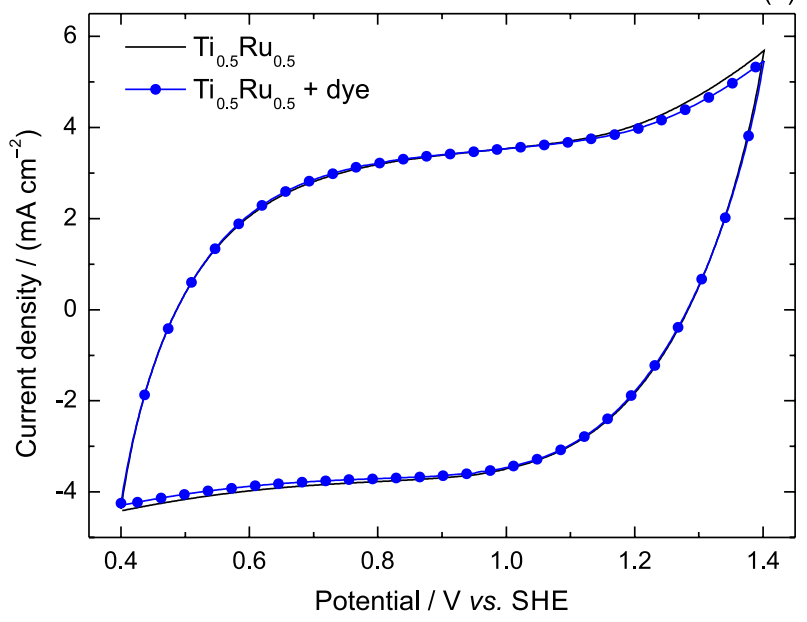

(e)

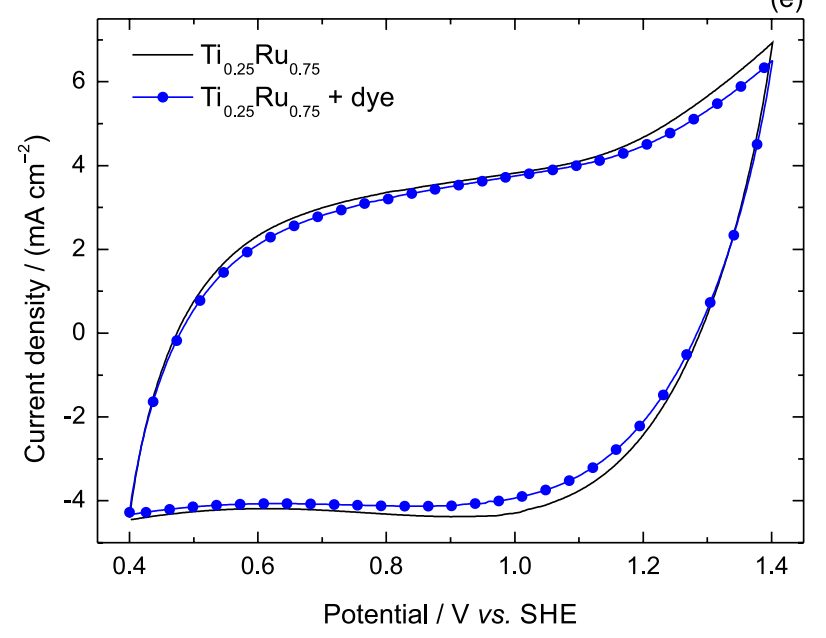

Figure 5. Cyclic voltammetry curves taken in a $0.1 \mathrm{~mol} \mathrm{~L}^{-1} \mathrm{NaCl}$ medium in ambient conditions, in the presence (black line) and absence of dye (dotted line) for all studied electrodes: (a) $\mathrm{Ru}$, (b) $\mathrm{Ti}$, (c) $\mathrm{Ti}_{0.75} \mathrm{Ru}_{0.25}$, (d) $\mathrm{Ti}_{0.5} \mathrm{Ru}_{0.5}$ and (e) $\mathrm{Ti}_{0.25} \mathrm{Ru}_{0.75}$.

Figure $5 \mathrm{~b}$ shows the responses taken at the $\mathrm{Ti}$ electrode, where the reduction of currents can be seen, as expected, demonstrating that in presence of the dye, the active sites of the electrode have a reduced current conduction capacity due to the strong adsorption of the organic compounds. This reduction is more severe in the areas of OER, which is a catalytic reaction that needs active sites available on the electrode surface so that the initial adsorption of ions containing oxygen can happen. Therefore, a reduction in the OER potentials confirms 
the hypothesis of a strong adsorption of the dye on the surface of the electrode.

Figure $5 \mathrm{c}$ shows the cyclic voltammetric response obtained for $\mathrm{Ti}_{0.75} \mathrm{Ru}_{0.25}$, in which a smaller voltammogram is noted when compared with the observed at the Ru electrode; however the shape of the curves are still very similar to those seen for the ruthenium electrode. Therefore, even though the electrode presented a slighter current density performance, it implies that even when the Ti amounts are more prevalent, the lower amounts of $\mathrm{Ru}$ on the electrode are still the one adjusting the electrode performance. This emphasizes the relevance and importance of $\mathrm{Ru}$ as an electric carrier.

Figure $5 \mathrm{~d}$ shows the cyclic voltammogram of $\mathrm{Ti}_{0.5} \mathrm{Ru}_{0.5}$, in which as expected, there is an average behavior of the electrode, presenting a voltammogram that is somewhat the intermediate between the $\mathrm{Ti}$ and Ru electrodes.

As for Figure 5e, the $\mathrm{Ti}_{0.25} \mathrm{Ru}_{075}$ electrode, which presented the highest roughness, and should consequently present the highest surface area. This area is a positive feature for both electrochemical and photocatalytic reactions. Although the voltammetric results were very good, they do not agree with the porosity assumption of a consequent better reaction in a higher porosity system. However, the results found for this electrode were inferior to the electrode containing only $\mathrm{Ru}$ and further study to state the best electrode for the system is required.

The larger electroactive area indicates that the electrode is capable to carry on a larger amount of electrochemical reactions in the solution-electrode interface, and therefore, will present a higher treatment rate/surface area. Therefore, the Ru electrode presenting the larger area would be indicated as the best electrode for the system disagreeing with the roughness results presented on the AFM analysis.

Here, it is clear that not only these assumptions are responsible for the efficiency of an electrode in a photoelectrocatalytic system, being also influenced by other factors, such as synergy of the precursors applied.

Figure 6 shows the cyclic voltammograms of all the developed electrodes overlaid in order to compare their behavior in a $0.1 \mathrm{~mol} \mathrm{~L}^{-1} \mathrm{NaCl}$ solution in absence of dye. This analysis was made to assess the voltammograms for all electrodes considering the amounts of $\mathrm{Ru}$ and Ti involved in their preparation. Considering only the voltammograms of $\mathrm{Ru}$ and $\mathrm{Ti}$, it is clearly seen that $\mathrm{Ru}$ has a much wider voltammogram showing the highest current density therefore, representing a more efficient composite of an electrode. As for Ti, its capacity of current carrying is extremely limited and practically irrelevant when analyzing an electrode with only Ti in its composition.

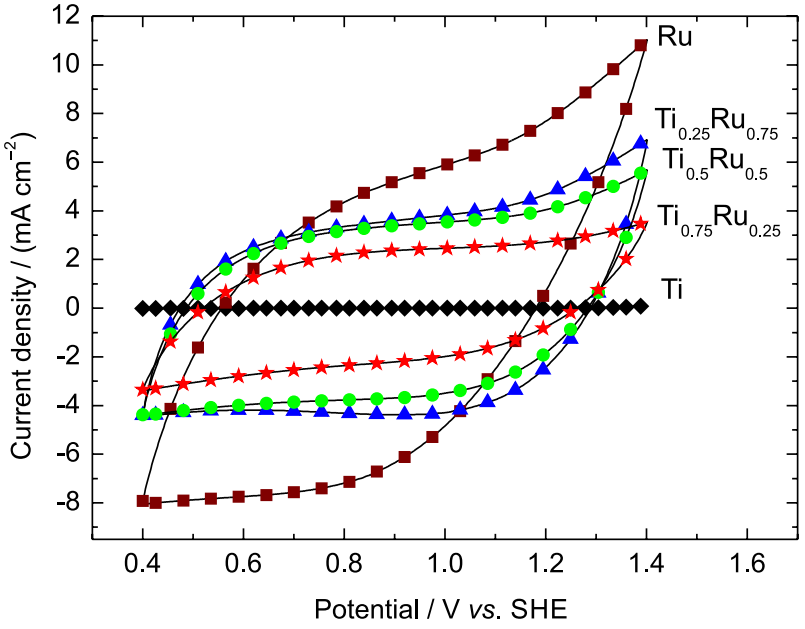

Figure 6. Cyclic voltammetry results taken for all studied electrodes at $0.05 \mathrm{~V} \mathrm{~s}^{-1}$ in a $0.1 \mathrm{~mol} \mathrm{~L}^{-1} \mathrm{NaCl}$ medium in ambient conditions and absence of dye.

When mixed in different proportions of Ti:Ru, however, the electrode behavior changes and stands in a position somewhat proportional to the composition contained in each electrode, considering the influence of Ru. Therefore, on the $\mathrm{Ti}_{0.75} \mathrm{Ru}_{025}$ electrode, a slighter voltammogram can be seen showing a tendency of behaving as an Ti electrode; the $\mathrm{Ti}_{0.5} \mathrm{Ru}_{0.5}$ electrode shows a very median behavior presenting aspects of what should be expected for an electrode composed of proportional $50 \%$ of each component also behaving as expected.

Among the mixed electrode, the electrode with best outcome was the $\mathrm{Ti}_{0.25} \mathrm{Ru}_{0.75}$, which has a high concentration of ruthenium. This outcome is in accordance to that found by Pelegrini et al. ${ }^{16}$ that prove the synergistic effects in photoelectrocatalysis was related to formation of $\cdot \mathrm{OH}$ on $\mathrm{RuO}_{2}$ from water discharge and on $\mathrm{TiO}_{2}$ via reaction simultaneously due to the holes generated by the photoirradiation.

The modified surface deposition suggests that when mixing these components, they interact and the Ti:Ru will present a different surface organization due to influences of the electronic field interactions and straining influence. ${ }^{17}$

\section{Indanthrene blue photoelectrodegradation}

From the slope in Figure 7a, it can be seen that aside from the Ti electrode (triangles), all the other electrodes present a considerable treatment performance, reducing the initial concentration to levels less than $80 \%$ on the $\mathrm{NaCl}$ solution system. The best performance in this system was seen for the $\mathrm{Ti}_{0.25} \mathrm{Ru}_{0.75}$ electrode where the concentration of dye varies from 61.20 to $6.886 \mathrm{mg} \mathrm{L}^{-1}$, presenting an $88.72 \%$ of color removal. 
As for comparison, Figure $7 \mathrm{~b}$ shows the performance of the same electrodes in a $\mathrm{Na}_{2} \mathrm{SO}_{4}$ solution where a reduced degradation outcome can be seen. The $\mathrm{Ti}_{0.25} \mathrm{Ru}_{0.75}$ electrode was still the one which presented the best results with a $27.33 \%$ of efficiency, reducing the dye initial concentration from 61.20 to $44.47 \mathrm{mg} \mathrm{L}^{-1}$. The dye concentration values were obtained using a calibration curve (data not shown).
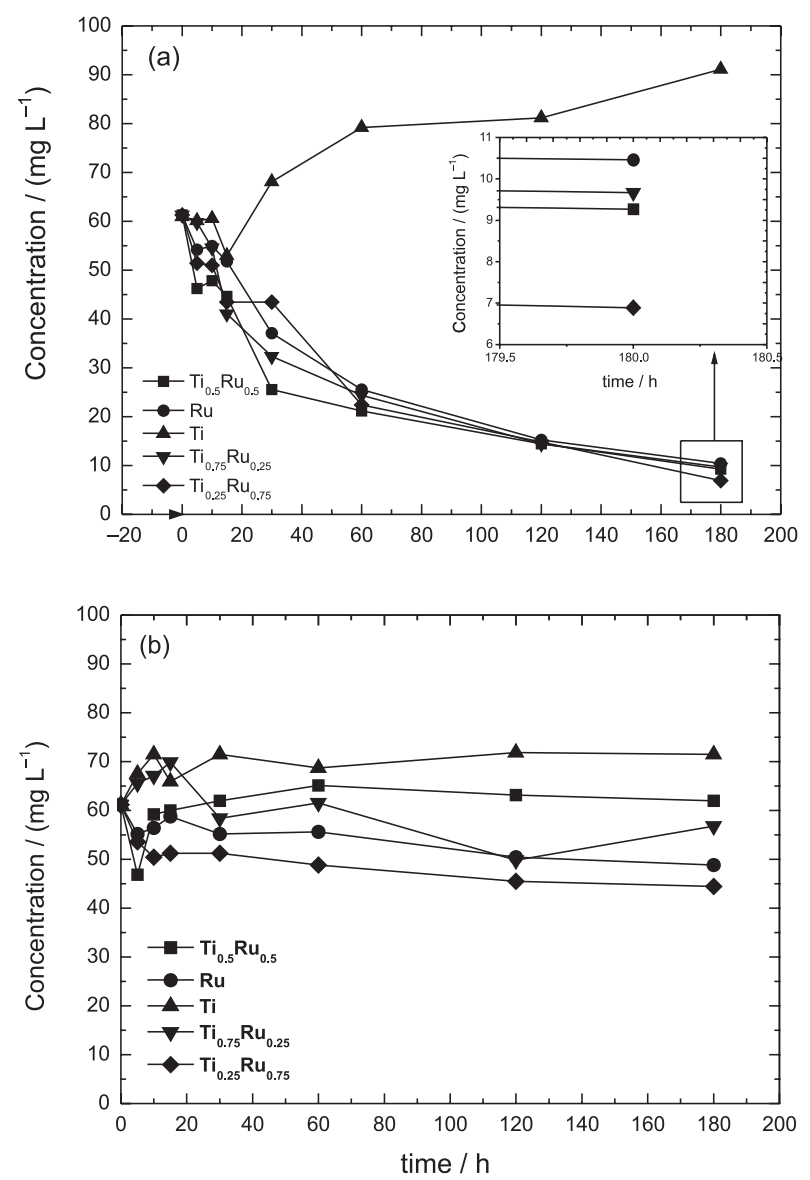

Figure 7. Indanthrene blue degradation in (a) $\mathrm{NaCl}, \mathrm{pH} 6.43$ and (b) $\mathrm{Na}_{2} \mathrm{SO}_{4}, \mathrm{pH} 6.77$ solutions at all the developed electrodes for $3 \mathrm{~h}$ of treatment, in ambient temperature and without current control in presence of the UV lamp.

The electrodes with high performance in Figure 7 are the ones with ruthenium in their composition, particularly $\mathrm{Ti}_{0.25} \mathrm{Ru}_{0.75}$, in an ion chloride solution. When comparing the electrodes in sodium chloride and sodium sulfate solution, in general, the electrodes in sodium chloride solution tend to present a better performance and thus a better dye removal. This is because the oxidation of ions chloride lead to the formation of molecular chlorine, hypochlorous acid or hypochlorite depending on the $\mathrm{pH}$ of the solution. These tend to oxidize organic compounds close to the anode or in the solution, the reactions that describe these processes are seen in equations 3 to 6 :
$2 \mathrm{CL}^{-} \rightarrow \mathrm{Cl}_{2}+2 e^{-}$

$\mathrm{Cl}_{2}+\mathrm{H}_{2} \mathrm{O} \rightarrow \mathrm{HOCl}+\mathrm{H}^{+} \mathrm{Cl}^{-}$

$\mathrm{HOCl} \leftrightarrow \mathrm{H}^{+}+\mathrm{OCl}^{-}$

Organic compounds $+\mathrm{OCl}^{-} \rightarrow \mathrm{CO}_{2}+\mathrm{Cl}^{-}+\mathrm{H}_{2} \mathrm{O}$

Previous studies ${ }^{1,19}$ reported specific generation of chlorine ions according to the $\mathrm{pH}$ seen for the medium in a photoelectrocatalytic study. Therefore, the best degradation was seen at $\mathrm{pH}<6.0$ for chloride medium and $\mathrm{pH}>10$ for sulfate medium. The strong degradation seen for $\mathrm{NaCl}$ in acidic medium was attributed to the large ability of the holes to oxidize $\mathrm{Cl}^{-}$to active chlorine species, such as $\mathrm{Cl}_{2}$ and $\mathrm{ClO}^{-}$and other radical such as $\mathrm{Cl}^{\circ}$ and $\mathrm{Cl}_{2}{ }_{2}$, which oxidize more quickly than heterogeneous ${ }^{\circ} \mathrm{OH}$ produced in $\mathrm{Na}_{2} \mathrm{SO}_{4}$ reactions.

As for the alkaline solutions, a strong inhibition of the generation of chlorinated oxidants from $\mathrm{Cl}^{-}$occurs, desacelerating the destruction of pollutants. Thus, considering both solutions as slightly acid, the inhibition effect is not expected. Although in the $\mathrm{Na}_{2} \mathrm{SO}_{4}$ medium, a lower degradation performance was seen, which can be attributed to the absence of chloride species.

Further studies carried out by Dai et al..$^{20}$ using a wet electrocatalytic oxidation system confirm the tendency of a lower $\mathrm{pH}$ representing a better outcome when considering electrochemical systems. The ${ }^{\circ} \mathrm{OH}$ formation, seen at lower $\mathrm{pH}$, lead to a higher degradation of organic pollutants (such as antraquinones dyes), due to oxidation of hydroxyl radicals. When alkaline conditions are considered, the degradation is carried out by hydroxyl savages, such as $\mathrm{CO}_{3}{ }^{2-}$.

For the Ti electrodes in $\mathrm{NaCl}$ medium, the absorbance results indicate an increase of the system concentration $\left(\mathrm{mg} \mathrm{L}^{-1}\right)$ after the first $30 \mathrm{~min}$. This behavior can be explained by the electrode degradation seen in this case. After $30 \mathrm{~min}$ of treatment, the Ti electrode tended to disinegrate, generating flakes as a consequence, increasing the turbidity.

Other studies also present a better effluent degradation in $\mathrm{NaCl}$ medium than $\mathrm{Na}_{2} \mathrm{SO}_{4}$ due to the additional oxidation of organics with active chlorine species. ${ }^{1}$ Furthermore, studies developed by López-Grimau and Gutiérrez showed that at lower currents, the oxidation process occurs differently in $\mathrm{Na}_{2} \mathrm{SO}_{4}$ and $\mathrm{NaCl}$. For the latter the oxidation proceeds mainly through active chlorine species which leads to important energy consumption saving. The same study also highlighted that the system is $\mathrm{pH}$ independent in presence of $\mathrm{NaCl}$, which was also tested in this study. 


\section{Influence of chloride concentration}

The dissolution of indanthrene blue on sodium chloride was done for various concentrations to determine the best $\mathrm{NaCl}$ concentration for our system. The first experiments had a $0.1 \mathrm{~mol} \mathrm{~L}^{-1}$ concentration, thus studies with a 0.025 , 0.05 and $0.2 \mathrm{~mol} \mathrm{~L}^{-1}$ of $\mathrm{NaCl}$ were also done. The results of these modifications can be seen in Figure 8 .

The best results for absorbance reduction were obtained for the $0.05 \mathrm{~mol} \mathrm{~L}^{-1} \mathrm{NaCl}$ concentration, showing a reduction from 1.72 to $0.027 \mathrm{~mol} \mathrm{~L}^{-1}$ of dye concentration, which represents a $97.19 \%$ efficiency of color removal.

However, the best results were expected to be found for the system with highest concentrations of $\mathrm{NaCl}$ due to the higher disposition to form chloride ions that are important in the color removal process, as explained earlier. The expected result was not obtained because in the system with highest concentration of $\mathrm{NaCl}$, the electrode was destroyed, forming white-like flakes that interfered in the absorbance analysis.

As previously described, ${ }^{1}$ chloride ions in acid medium are the most influent factor for the degradation of organic compounds. Considering the selected medium at a $\mathrm{pH}$ 6.43, classified as slightly acid, it is expected that the increase in $\mathrm{NaCl}$ present in the medium generate more chloride ionsand therefore resulting in an increase of degradation. The medium with higher amount of $\mathrm{NaCl}$ presented such an amount of chloride ions that during the process of degrading the antraquinone dye it also degraded the electrode destroying the eletrocatalytic system. Therefore, an uncontrolled amount of $\mathrm{NaCl}$ in the medium does not necessarily represent an improvement for the degradation reaction.

In fact, if the final effluent treated with a $0.2 \mathrm{~mol} \mathrm{~L}^{-1}$ $\mathrm{NaCl}$ concentration is left to rest for nearly $1 \mathrm{~h}$, the decantation suffered by the system will result in the cleanest of all systems, but that would indicate a different proposal of wastewater treatment system for industrial or municipal effluents, consisting of a photoelectrocatalysis associated with a posterior decanting process. So, for the purpose of this study, the $\mathrm{NaCl}$ concentration chosen was $0.05 \mathrm{~mol} \mathrm{~L}^{-1}$ that did not demand a secondary treatment system.

\section{Current density influence analysis}

Previous studies show that the current density of the system directly influence the growth of flakes and the size of bubbles evolved, determining the retention time and energy cost of the process. ${ }^{22}$ Thus, degradation experiments were carried out applying 150, 100, 50 and $25 \mathrm{~mA} \mathrm{~cm}^{-2}$ with the

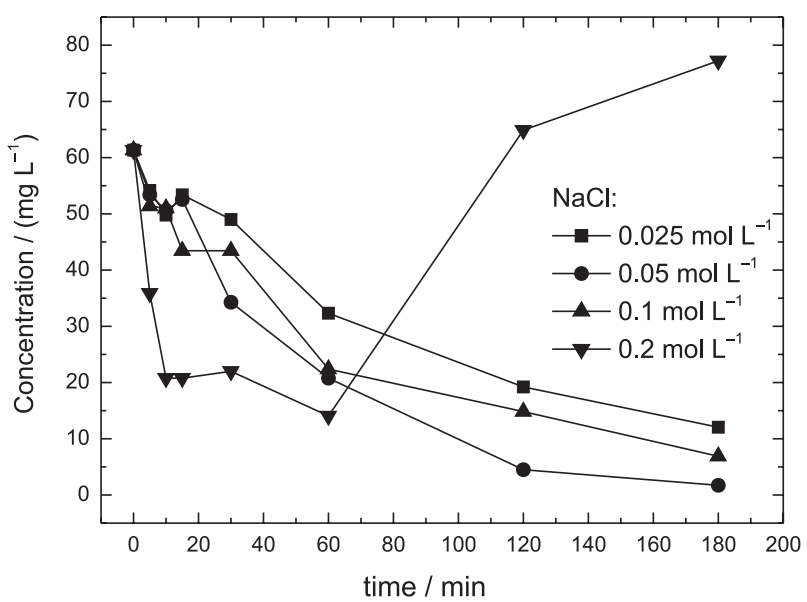

Figure 8. Indanthrene blue concentration profiles for effluent photoelectrocatalytically treated using $\mathrm{Ti}_{0.25} \mathrm{Ru}_{0.75}$ electrode with different concentrations of $\mathrm{NaCl}$ for $3 \mathrm{~h}$ of treatment, at ambient temperature, with neither $\mathrm{pH}$ nor current control.

$\mathrm{Ti}_{0.25} \mathrm{Ru}_{0.75}$ electrode in a $0.05 \mathrm{~mol} \mathrm{~L}{ }^{-1} \mathrm{NaCl}$ solution. The data yielded represent the dye concentrations according to calibration curves (data not shown), in the established sampling time and are represented in Table 1.

Table 1. Absorbance values (arbitrary unit) for dye degradation using $\mathrm{Ti}_{0.25} \mathrm{Ru}_{0.75}$ electrode in a $0.05 \mathrm{~mol} \mathrm{~L}^{-1} \mathrm{NaCl}$ solution at different currents, with neither $\mathrm{pH}$ nor temperature control

\begin{tabular}{lcccc}
\hline $\begin{array}{l}\text { Current density / } \\
\left(\mathrm{mA} \mathrm{cm}^{-2}\right)\end{array}$ & \multicolumn{5}{c}{ Sampling time / h } \\
\cline { 2 - 5 } 150 & 2.502 & 0.657 & 0.288 & 0.009 \\
100 & 2.502 & 0.846 & 0.459 & 0.099 \\
50 & 2.502 & 2.169 & 0.918 & 0.144 \\
25 & 2.502 & 2.043 & 2.025 & 0.207 \\
\hline
\end{tabular}

The data above show that at $150 \mathrm{~mA} \mathrm{~cm}^{-2}$ the system was best improved, showing the lowest absorbance value. A decrease of absorbance from 2.502 to 0.009 was experienced, for which according to the calibration curve, represents a dye concentration of $0.93 \mathrm{~mol} \mathrm{~L}^{-1}$, the removal efficiency was of $99.17 \%$. The performance of the electrode at $100 \mathrm{~mA} \mathrm{~cm}^{-2}$ should also be considered since in that system a reduction of $95.59 \%$ was obtained. The same cannot be said for the 50 and $25 \mathrm{~mA} \mathrm{~cm}^{-2}$ currents, which were less effective, yielding a reduction of 93.8 and $91.29 \%$, respectively, after decantation.

These results are in accordance to literature, ${ }^{23}$ in which an increase of color removal was seen for higher current intensity. However, while analyzing industrial systems, it is important to keep in mind the viability and applicability of such study, and therefore propose systems that are profitable and applicable. In this manner, the study was continued 
using a $100 \mathrm{~mA} \mathrm{~cm}^{-2}$ current as ideal, considering that it also had good outcomes and represents the best cost-efficiency relation overall.

Furthermore, considering studies developed by Haan et al. ${ }^{24}$, in which the influence of $\mathrm{pH}$ in current density showed that when increasing the $\mathrm{pH}$ of weakly acidic solutions, enhancements in the current density at a given potential are seen. In that research, a 30 fold increase of current density at $0.22 \mathrm{~V}$ was seen when a $\mathrm{pH}$ variation from 1 to 5 was present. This effect is attributed to the negative shift of $\mathrm{CO}$ oxidation potential with the increase in $\mathrm{pH}$, which would poison the electrode surface. Therefore, the $\mathrm{pH}$ optimization could represent a poising preventive tool.

\section{Temperature influence analysis}

Experiments were carried out at 35,50 and $75{ }^{\circ} \mathrm{C}$ to estimate the influence of temperature in the system studied. The results can be seen in Table 2 .

Table 2. Absorbance values (arbitrary units) for dye degradation using $\mathrm{Ti}_{0.25} \mathrm{Ru}_{0.75}$ electrode in a $0.05 \mathrm{~mol} \mathrm{~L}^{-1} \mathrm{NaCl}$ solution at $100 \mathrm{~mA} \mathrm{~cm}{ }^{-2}$, with no $\mathrm{pH}$ control

\begin{tabular}{lcccc}
\hline \multirow{2}{*}{ Temperature $/{ }^{\circ} \mathrm{C}$} & \multicolumn{4}{c}{ Sampling time $/ \mathrm{h}$} \\
\cline { 2 - 5 } & 0 & 1 & 2 & 3 \\
\hline 35 & 2.502 & 0.882 & 0.639 & 0.054 \\
50 & 2.502 & 0.900 & 0.522 & 0.072 \\
70 & 2.502 & 1.233 & 0.900 & 0.171 \\
\hline
\end{tabular}

From the data, it can be concluded that at $35{ }^{\circ} \mathrm{C}$ the highest degradation degrees were seen, reducing the initial concentrations from 110.99 to $2.91 \mathrm{~mol} \mathrm{~L}^{-1}$, representing a removal efficiency of $96.66 \%$. At $70{ }^{\circ} \mathrm{C}$, the removal efficiency was $92.72 \%$. At $50{ }^{\circ} \mathrm{C}$, a reduction from the initial concentration of 110.99 to $3.71 \mathrm{mg} \mathrm{L}^{-1}$ was seen representing a $96.66 \%$ removal efficiency. These results show that the temperature dependency of the system is low; in a scenario where the temperature is elevated in two folds, the influence in the color removal is not proportional. Therefore, a linear dependency is not seen since the color removal does not follow temperature variations linearly.

On the other hand, considering the degradation of a textile effluent where color of the contaminant is one of the most important features considered, as the temperature increases, the recombination of charge carriers and also the desorption process of adsorbed reactant species can be seen, resulting in a decrease of activity. ${ }^{25}$ This was confirmed in our experiment, in which an increase in the formation of flakes was seen for the system at $70{ }^{\circ} \mathrm{C}$. These flakes accumulate on the surface of the solution increasing the absorbance capacity of the effluent. The remaining systems did not present representative flocculation, which indicates that the flocculation is related to high temperatures.

Previous studies developed by Bonfatti et al. ${ }^{26}$ reinforce the mild influence of temperature in the photoelectrocatalytic system, since the electrochemical process allows more than one reaction simultaneously, competing with one another, and with the photocatalytic reactions. Therefore, the temperature has little influence in the system.

\section{$\mathrm{pH}$ dependency analysis}

By varying the $\mathrm{pH}$ of the solution, the surface charge of $\mathrm{TiO}_{2}$ changes, shifting the potential of catalytic reaction, therefore, the adsorption of dyes on the surface is modified, varying the system reaction rate. Under an acid or alkaline condition, the surface of titanium can be protonated or deprotonated according to equations 7 and $8: 25$

$\mathrm{TiOH}+\mathrm{H}^{+} \rightarrow \mathrm{TiOH}_{2}^{+}$

$\mathrm{TiOH}+\mathrm{OH}^{-} \rightarrow \mathrm{TiO}^{-}+\mathrm{H}_{2} \mathrm{O}$

Once the ideal electrode, current, temperature and effluent concentration were determined, the $\mathrm{pH}$ values were studied as a way to further enhance the system. Extensive study to determine the ideal $\mathrm{pH}$ for the system was done; previous report ${ }^{27}$ stated that at $\mathrm{pH}<6.0$, the degradation is faster in chloride medium. The acidic medium created in this chloride medium is responsible for the large ability of the holes formed according to equation 1 , to oxidize $\mathrm{Cl}^{-}$to active chlorine species $\left(\mathrm{Cl}_{2}, \mathrm{HClO}\right.$ and $\left.\mathrm{ClO}^{-}\right)$, which come to oxidize organics faster than heterogeneous ${ }^{\circ} \mathrm{OH}$ produced in a $\mathrm{Na}_{2} \mathrm{SO}_{4}$ system. The opposite can be seen in alkaline solutions where there is strong inhibition of the generation of chlorinated oxidants from $\mathrm{Cl}^{-}$.

All the previous experiments were done without a $\mathrm{pH}$ adjustment, considering initial $\mathrm{pH}$ already described previously. For the following steps, the $\mathrm{pH}$ was fixed for 5 values, two of them acids ( $\mathrm{pH} 3$ and 5), one neutral ( $\mathrm{pH} 7$ ) and two alkaline ( $\mathrm{pH} 9$ and 12). The initial $\mathrm{pH}$ adjustments were done by adding $1 \mathrm{~mol} \mathrm{~L}^{-1} \mathrm{HCl}$, so that the effluent becomes acid and for the effluent to become alkaline $1 \mathrm{~mol} \mathrm{~L}^{-1} \mathrm{NaOH}$ was added.

Therefore, considering previous experiments, the photoelectrocatalysis was carried out at a $100 \mathrm{~mA} \mathrm{~cm}{ }^{-2}$ current, at $35{ }^{\circ} \mathrm{C}$, with the $\mathrm{Ti}_{0.25} \mathrm{Ru}_{0.75}$ electrode in a $0.05 \mathrm{~mol} \mathrm{~L}^{-1} \mathrm{NaCl}$ solution, thberesults can be seen in Figure 9. 
The greatest absorbance decay was obtained for $\mathrm{pH} 3$, in which the initial absorbance of 2.565 is reduced to 0.027 , yielding a removal efficiency of $98.49 \%$. The second best result is at $\mathrm{pH} 7$, in which the removal efficiency was of 97.38\%, seen in Figure 9.

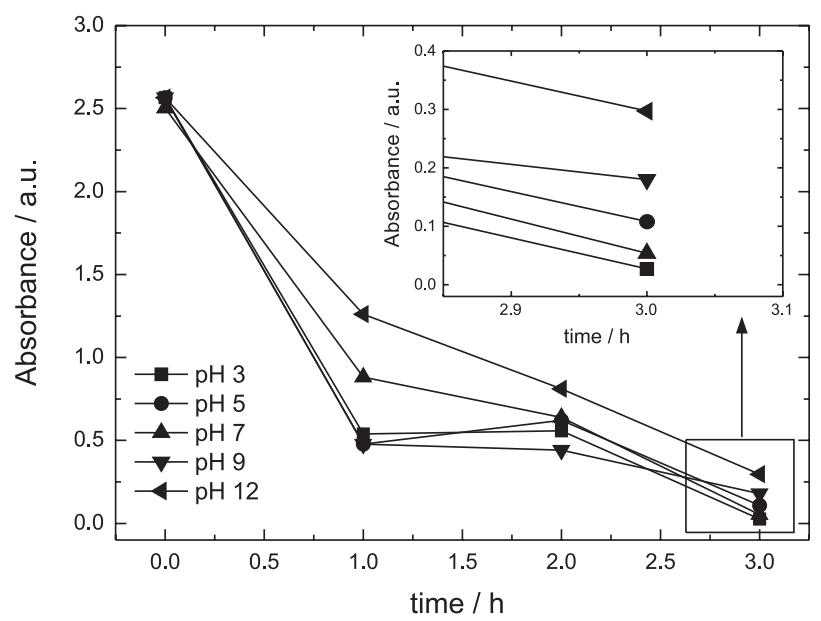

Figure 9. Decay of indanthrene blue dye absorbance with time during its photoelectrochemical degradation on $\mathrm{Ti}_{0.25} \mathrm{Ru}_{0.75}$ electrode, immersed in a $0.05 \mathrm{~mol} \mathrm{~L}^{-1} \mathrm{NaCl}$ medium and for different $\mathrm{pH}$ values, using $100 \mathrm{~mA} \mathrm{~cm}^{-2}$ of current at $35^{\circ} \mathrm{C}$. Inset: enlargement of the last part of the decay curves.

At slightly acid $\mathrm{pH}$, there is a tendency to show better results than at alkaline ones. However, it is not possible to assume that lower $\mathrm{pH}$ will necessarily indicate a higher degree of effluent degradation, once that the second best performance was seen at $\mathrm{pH} 7$ (neutral), while $\mathrm{pH}$ 5,9 and 12 showed a final concentration of $5.3 \mathrm{~mol} \mathrm{~L}^{-1}$ (95.34\%), $8.47 \mathrm{~mol} \mathrm{~L}^{-1}(92.55 \%), 13.64 \mathrm{~mol} \mathrm{~L}^{-1}(88.01 \%)$, respectively.

Carneiro et al. ${ }^{27}$ stated that at $\mathrm{pH}<6.0$ in $\mathrm{NaCl}$ medium and at $\mathrm{pH}>10$ in $\mathrm{Na}_{2} \mathrm{SO}_{4}$ medium, a maximum photoelectrocatalytic degradation is seen in a wastewater treatment. In this case, the main dye treated is an azo dye from the textile industry and the catalyst considered are nanoporous $\mathrm{TiO}_{2}$ thin-film electrodes. Considering the resemblance with our study, it should be pointed out that similar results were seen.

Thus for the present study, $\mathrm{pH} 7$ and 3 were considered ideal, but in an industrial scale, the last would not be the best choice, since according to local legislation, ${ }^{28}$ such acid $\mathrm{pH}$ would be over the limit of legal acceptance. Such condition would obligate the company to consider a posterior treatment for $\mathrm{pH}$ adjustment.

\section{Dye concentration dependency analysis}

The last analysis done considered the variation on dye concentration, taking it from the initial $60 \mathrm{ppm}$ and varying to $25,50,150$ and $200 \mathrm{ppm}$. The results of these variations were obtained by spectrophotometer absorbance analysis in which the final concentration of dye can be estimated through calibration curves (data not shown).

All results obtained were relevant since the values of absorbance of the dye at the final of the treatment are very similar (Figure 10) being needed an enlargement of this region, as observed in the inset of Figure 10. The 100 ppm concentration showed the best results with a $98.94 \%$ dye removal. A non-linear relation is established between the dye concentration and its removal at the end of the photoelectrocatalysis reaction. For 25, 50, 100, 150 and $200 \mathrm{ppm}$, the dye removal efficiency was of 96.7, 98.7, $98.94,98.11$ and $98.55 \%$, respectively. A linear relation, such as, an increased removal when there is an increase in concentration was expected, however, this was not confirmed as seen in Figure 10.

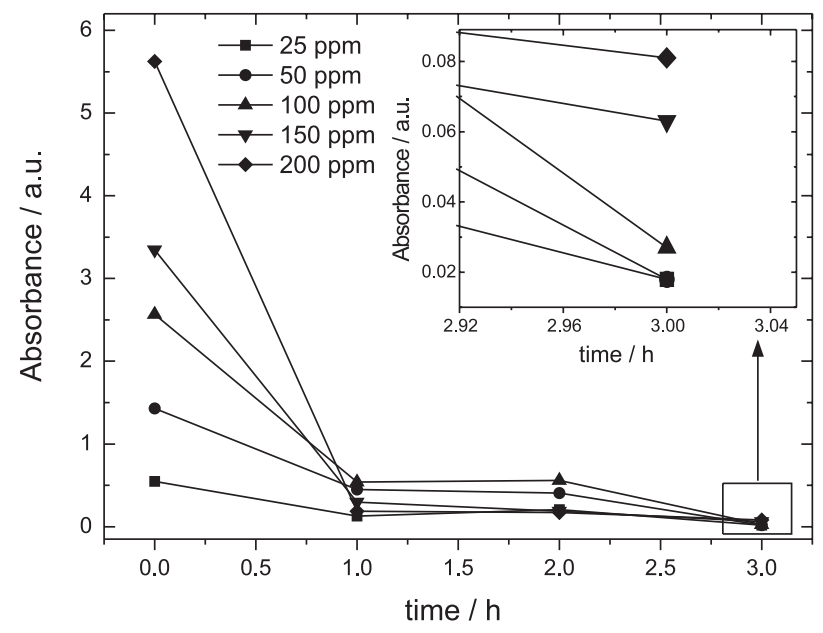

Figure 10. Decay of indanthrene blue dye absorbance with time during its photoelectrochemical degradation on $\mathrm{Ti}_{0.25} \mathrm{Ru}_{0.75}$ electrode, immersed in a $0.05 \mathrm{~mol} \mathrm{~L}^{-1} \mathrm{NaCl}$ medium and for different initial concentration of dye, using $100 \mathrm{~mA} \mathrm{~cm}^{-2}$ of current at $35^{\circ} \mathrm{C}$ and $\mathrm{pH} 3$. Inset: enlargement of the last part of the decay curves.

Although the color removal seems to vary independently from the dye concentration, all systems presented a very high treatment efficiency indicating that the photoelectrocatalysis system developed represents an effective way to reduce dye concentrations for all initial concentrations studied here. As for industrial applications, this is a very positive system feature, indicating that a previous concentration adjustment is not necessary, making the system cheaper and more viable.

\section{Conclusions}

In this study, 5 different compositions of electrodes in order to achieve an efficient photoelectrocatalytic system for 
indanthrene blue wastewater treatment were synthesized. Physical and electrochemical characterizations were carried out to further investigate the electrode properties. At last, the $\mathrm{pH}$, medium concentration, temperature, applied current and dye concentrations were also varied aiming to determine the influence of these variables in the dye polluted wastewater treatment performance and also to establish optimized operational conditions.

Since the AFM and voltammograms pointed out the same electrode as the potentially best one to yield the best color removal treatments, and considering that this electrode presents the highest roughness and the higher voltammetric charge, further studies were developed for various chloride concentrations, applied currents, cell temperatures, solution $\mathrm{pH}$ and dye concentrations, presenting various outcomes.

While varying the chloride concentration (0.025-0.2 mol L $\mathrm{L}^{-1}$ ), it was expected that the highest the concentration, the best the outcomes; however the flocculation seen when applying high $\mathrm{NaCl}$ concentrations was a limiting factor for this affirmation. Surprisingly, the highest dye removal was then observed at $0.05 \mathrm{~mol} \mathrm{~L}^{-1} \mathrm{NaCl}$.

The current analysis similarly considers that the best outcome should be seen for the highest current, ${ }^{23}$ which was confirmed in our study, in which the $150 \mathrm{~mA} \mathrm{~cm}^{-2}$ system presented the best outcome (99.17\% of color removal). However for industrial applications, it is important to consider the energy consumption and the use of a lower current system to prevent excessive energy costs. Thus, the $100 \mathrm{~mA} \mathrm{~cm}^{-2}$ system was considered ideal.

When varying the temperature of the system, a similar behavior for the chloride concentration and current variations is expected, where an inversely linear behavior was supposed to be seen. The higher the temperature, the lowerthe system efficiency should be. This was confirmed due to the formation of flocculation and the best operational temperature for this system was considered $35^{\circ} \mathrm{C}(96.66 \%$ of color removal).

At $\mathrm{pH} 3.0$, the treatment efficiency was of $98.49 \%$ of color removal. However, such an acid $\mathrm{pH}$ would negatively influence the water quality and cause a different source of environmental damage to the groundwater system and therefore, represent a secondary form of pollution. Thus, due to the small differences of treatment noticed in all $\mathrm{pH}$ systems, the $\mathrm{pH}$ chosen to carry out the remaining analysis was $\mathrm{pH} 7$.

For the dye concentration analysis, at all concentrations, the final system $\left(0.05 \mathrm{~mol} \mathrm{~L}^{-1} \mathrm{NaCl}, 100 \mathrm{~mA} \mathrm{~cm}^{-2}, 35^{\circ} \mathrm{C}\right.$, pH 7) using $\mathrm{Ti}_{0.25} \mathrm{Ru}_{0.75}$ electrode presented good outcomes with very similar treatment efficiency independent of the initial dye concentration.
As for the byproducts produced during the degradation of anthraquinone dyes, previous studies developed by Fanchiang et al. ${ }^{29}$ identified the formation of phthalic acids, aldehydes, 1,3-indanone and nitrogen containing compounds. In general, these compounds present structures that are easier to break than the original anthraquinone dye, which eases natural degradation. Further studies to precisely identify the compounds formed in the blue indanthrene degradation are required but, unless recombination is identified, the byproducts formed are expected to be of lower molecular weight and easier to degrade.

These results indicate the photoelectrochemical system developed in this study is potentially capable of treating systems with a wide range of concentration of dyes which is a very important factor in industrial applications once these do not necessarily present the same dye concentration at all times. However, they depend on the same treatment efficiency to constantly be in accordance to legislation.

Thus, the system represents a promising industrial applicability although it also presents a limited work range and should always be maintained inside the workable gap. However, in various situations, the system is capable of degrading the electrode and causing different amounts of flocculation, which would represent a secondary form of pollution and increasing costs. Further study could be developed in order to analyze and enhance the system stability providing a wider work range.

\section{Acknowledgements}

The authors thank the National Council for Scientific and Technological Development (CNPq) (Proc.: 304018/2009-0) from Brazil for the scholarships and financial support for this work.

\section{References}

1. Martínez-Huitle, C. A.; Brillas, E.; Appl. Catal., B 2009, 87, 105.

2. Moussavi, G.; Mahmoudi, M.; J. Hazard. Mater. 2009, 168, 806.

3. Deng, D.; Guo, J.; Zeng, G.; Sun, G.; Int. Biodeterior. Biodegrad. 2008, 62, 263.

4. Novotný, C.; Dias, N.; Kapanen, A.; Malachová, K.; Vándrovcová, M.; Itävaara, M.; Lima, N.; Chemosphere 2006, 63, 1436.

5. Sirés, I.; Brillas, E.; Environ. Int. 2012, 40, 212.

6. Xie, Y. B.; Li, X. Z.; Mater. Chem. Phys. 2006, 95, 39.

7. Pechini, M.P.; US pat. 3,330,697 1967.

8. Mahshid, S.; Ghamsari, M. S.; Askari, M.; Afshar, M.; Lahuti, S.; Semiconduct. Phys. Quant. Elect. Optoelect. 2006, 9, 65. 
9. Chaari, I.; Feki, M.; Medhioub, M.; Bouzid, J.; Fakhfakh, E.; Jamoussi, F.; J. Hazard. Mater. 2009, 172, 1623.

10. Costa, C. R.; Botta, C. M. R.; Espindola, E. L. G.; Olivi, P.; J. Hazard. Mater. 2008, 153, 616.

11. Hočevar, M.; Krašovec, U. O.; Berginc, M.; Drazic, G.; Hauptman, N.; Topič, M.; J. Sol-Gel Sci. Technol. 2008, 48, 156.

12. Hao, H.; Zhang, J.; Microporous Mesoporous Mater. 2009, 121, 52 .

13. Zheng, L.; Sens. Actuators, B 2003, 88, 115.

14. Pizzini, S.; Buzzana, B.; Mari, C.; Rossi, L.; Torchio, S.; Mater. Res. Bull. 1972, 7, 449.

15. Catanho, M.; Malpass, G. R. P.; Motheo, A. J.; Quím. Nova 2006, 29, 983

16. Pelegrini, R.; Peralta-Zamora, P.; Andrade, A.R.; Reyes, J.; Duran, N.; App. Catal., B 1999, 22, 83.

17. Jiang, X.; Wang, T.; Environ. Sci. Technol. 2007, 41, 4441.

18. Scialdone, O.; Randazzo, S.; Galia, A.; Silvestri, G.; Water Res. 2009, 43, 2260.
19. Solano, A. M. S.; Araújo, C. K. C.; Melo, J. V.; Peralta-Hernandez, J. M.; Silva, D. R.; Martínez-Huitle, C. A.; Appl. Catal., B 2013, 130-131, 112.

20. Dai, Q.; Lei, L.; Zhang, X; Sep. Purif. Technol. 2008, 61, 123.

21. Lopez-Grimau, V.; Gutierrez, M.C.; Chemosphere 2006, 62, 106.

22. Chen, G.; Sep. Purif. Technol. 2004, 28, 11.

23. Montanaro, D.; Petrucci, E.; Chem. Eng. J. 2009, 154, 138.

24. Haan, J. L.; Masel, R. I.; Electrochim. Acta 2009, 54, 4073.

25. Rauf, M. A.; Ashraf, S. S.; Chem. Eng. J. 2009, 151, 10.

26. Bonfatti, F.; Battisti, A. De; Ferro, S.; Lodi, G.; Osti, S.; Electrochim. Acta 2000, 46, 305.

27. Carneiro, P. A.; Osugi, M. E.; Sene, J. J.; Anderson, M. A.; Zanoni, M. V. B.; Electrochim. Acta 2004, 49, 3807.

28. Sirvinskas, L.P.; Manual de Direito Ambiental, 5a. ed.; Editora Saraiva: São Paulo, Brasil, 2007.

29. Fanchiang, J.; Tseng, D.; Chemosphere 2009, 77, 214.

Submitted: November 1, 2012

Published online: March 15, 2013 